\title{
Developing the Innovative Engagement Scale (IES): An Instrument for the Study of Interactive Engagement
}

\section{Dr. Jonathan C. Hilpert, Georgia Southern University}

Jonathan C. Hilpert is an Associate Professor of Educational Psychology at Georgia Southern University. His research is focused on the specification of domain general learning models to science learning contexts in ways that integrate motivation, cognition, and engagement from a systems perspective.

\section{Dr. Jenefer Husman, Arizona State University}

Jenefer Husman received a doctoral degree in Educational Psychology from the University of Texas at Austin, in 1998. She served as an Assistant Professor at the University of Alabama from 1998 to 2002, when she moved to Arizona State University. In 2008 she was promoted by ASU to Associate Professor. Dr. Husman serves as the Director of Education for the Quantum Energy and Sustainable Solar Technology Center - an NSF-funded Engineering Research Center. Dr. Husman is an assistant editor of the Journal of Engineering Education, has been a guest editor of Educational Psychology Review, served on editorial board for top educational research journals, and currently sits on the editorial board of Learning and Instruction. In 2006 she was awarded the U.S. National Science Foundation CAREER grant award and received the Presidential Early Career Award for Scientists and Engineers from the President of the United States. She has conducted and advised on educational research projects and grants in both the public and private sectors, and served as an external reviewer for doctoral dissertations outside the U.S. She publishes regularly in peer-reviewed journals and books. Dr. Husman was a founding member and first President of the Southwest Consortium for Innovative Psychology in Education and has held both elected and appointed offices in the American Psychological Association (APA) and the Motivation Special Interest Group of the European Association for Research on Learning and Instruction.

Dr. Glenda Simonton Stump, Massachusetts Institute of Technology 


\title{
Developing the Innovative Engagement Scale (IES): An Instrument for the Study of Interactive Engagement
}

\begin{abstract}
This paper summarizes the development of the Innovative Engagement Scale (IES; TUES Type 1 DUE 1245018). The IES is an assessment instrument designed for researchers to gather evidence for how innovative instructional strategies impact student interactive engagement and classroom innovation. The instrument contains open ended and Likert scale items organized into five subsections that can be used to gather evidence for three constructs: a) innovative instructional strategies, b) interactive engagement, and c) student innovation. The items are designed to be administered online. The instrument was developed and tested over the course of three data collections $(\mathrm{N}=1365)$ in post-secondary energy science engineering courses.

Reliability and validity evidence as well key findings from analysis of student responses to the instrument are summarized. This material is based upon work supported by the National Science Foundation under Grant No. 1245018.
\end{abstract}

\section{Introduction}

Student engagement in classroom learning is an important construct in post-secondary STEM education research, particularly in the field of engineering education [1]. Research situates student engagement an essential cognitive, behavioral, and affective components of successful student outcomes, including academic achievement, persistence, and critical thinking [2]. Engagement constructs are typically positioned in domain general learning models as mediators between instruction and outcome variables. Accordingly, faculty in higher education are regularly encouraged to improve their instruction by using instructional strategies to improve student engagement, under the prevailing assumption that it will improve learning, achievement, and other important educational targets [3]. Despite the popularity of engagement research, extant findings suggest that the impact of instruction on student engagement, and the impact of engagement on student outcomes, is statistically small [4].

We have argued in our previous work that to improve our understanding of how instructional strategies impact student engagement, and in turn how student engagement is predictive of classroom innovation, engagement should be operationalized and studied from a complex systems perspective $[5,6]$. Because many instructional strategies increase classroom interaction, engagement constructs operationalized to measure ties between students, and their perception of the complex and dynamic qualities of their learning experiences, can help to provide a more complete picture of how instruction influences classroom systems, not just individual level cognitive processing or behavior. Furthermore, research suggests that classroom outcomes are often emergent in nature [7]. The coordinated action of many students cannot be completely reduced to the individual contributions of single actor in a classroom. Innovations, as operationalized according to economic research, typically fall into the category of emergent outcomes [8].

From this perspective, single engagement constructs operationalized at the individual level of analysis may not provide much predictive power or good evidence for how instruction influences student innovation in STEM classrooms. Targeting individual-level characteristics to study an 
interactive phenomenon may be faulty reasoning. To improve measurement, we have developed an assessment instrument (TUES Type 1 DUE 1245018) which operationalizes student engagement as a complex, interactive construct. The instrument contains open ended and likert scale items that can be used to gather evidence for a) innovative instruction, b) interactive engagement, and c) student innovation. The assessment instrument also contains short scenarios that can be administered to empirically align student responses with ABET outcomes regarding the ability to function on teams, identify and solve problems, and use techniques and skills necessary for engineering practice [9]. We have administered the instrument to a large sample of engineering students $(n=1365)$ from two research universities, along with other established measures of individual student engagement.

This paper summarizes the development of the Innovative Engagement Scale (IES) including the purpose of the instrument, the processing of drafting and administering the instrument, the sampling and analytic strategies that were used, as well as some of the key findings and conclusions. Implications of our findings for engagement research in post-secondary classrooms are also discussed. Interested parties are encouraged to contact the first author of this paper for a copy of the instrument technical manual.

\section{Purpose of the Project}

The overarching purpose of this project was to broaden and strengthen a theory of student engagement by defining forms of student interaction that are predictive of innovation in engineering classrooms, and providing evidence that these forms of engagement can be measured with confidence. The assessment is intended for use in post-secondary STEM classroom research. Complex systems research suggests that innovations typically emerge from interaction, whether among people in a lab or firms in an economy. Thus, an important sub goal was to develop an instrument that can be used to assess forms of interactive engagement that are predictive of innovation in the classroom. Furthermore, innovative instructional strategies in engineering education promote forms of classroom interaction that promote innovation. Thus, another important sub goal of the project was to develop items that can measure student perceptions of innovative instructional strategies. The combined set of items allowed us to examine a domain general innovative engagement model. See [10] for a complete review of this model.

\section{Instructional Strategies $\rightarrow$ Interactive Engagement $\rightarrow$ Student Innovation}

\section{Instrument Development}

The instrument development process spanned a two year period, and was broken down into the following overarching goals and target completion dates. Each of these major goals were broken down further into sub-goals for each project year. Table 1 provides a list of the overarching project goals followed by the sub-goals listed by year in the form of project accomplishments that provides a general overview of the project timeline and activities.

Table 1.

Project timeline including goals and accomplishments

Overarching Goals 
Develop Study Measures (Fall 2013)

Build Survey Website (Fall 2013)

Pilot Study Measures (Spring 2014)

Refine Measures (Spring 2014)

Test Revised Measures (Fall 2014)

Examine Invariance (Spring 2015)

Dissemination (Spring 2015)

\begin{tabular}{l}
\hline Year One Accomplishments (2013-14) \\
\hline Build the study website, including the data collection mechanism \\
Interview experts/Observe classes \\
Develop initial innovative engagement instrument \\
Pilot test the instrument at Georgia Southern University with 296 engineering students \\
Pilot test the instrument at Arizona State University with 210 engineering students \\
Examine the factorial structure and generate validity/ reliability evidence \\
Revise the instrument based on initial findings \\
Year Two Accomplishments (2014-15) \\
\hline Administer revised survey to 859 engineering education students at test sites \\
Reexamine factorial structure and examine structural equivalency between GSU and ASU \\
Generate second round of validity/ reliability evidence \\
Create technical manual for instrument with summary of evidence and instructions for use \\
Disseminate technical manual via website and conference presentations
\end{tabular}

\section{Drafting the Instrument}

The instrument was drafted based on classroom observations, discussion with experts, and a review of extant theory. Researchers involved with the project used observational classroom data, and reviewed relevant literature, to guide the development of a draft instrument, including engagement items, instructional strategy items, and example scenarios that described student group work. The draft instrument was shared with engineering educators, and the researchers discussed the content of the survey and solicited feedback. Then, the survey questions aligned with the study variables were shared with an outside project evaluator for review. Final adjustments were made, and the first version of the instrument was prepared for testing.

The assessment instrument is comprised open ended and Likert items and measures five components: innovative instructional strategies, classroom interactive experiences, interactive engagement, innovation, and ABET aligned group work scenarios. Students enter the survey and are asked to respond to a series of Likert items about instruction they receive in the engineering course from which they were recruited. After this, they are asked to imagine a recent time in their recruitment class that they engaged in a group activity or project and to complete open ended descriptions of these experiences. Then, students read and respond to a set of Likert scale items that describe interactive engagement and innovation targeted toward the experience they imagined. Students complete the survey by rating how well four classroom scenarios, aligned with ABET outcomes, match their own experiences.

\section{Administering and Revising the Instrument}

The survey is designed to be administered online and can be used with any online survey software. To administer the survey for development and testing, IRB approval was gained to 
recruit students from energy science engineering courses. A recruitment schedule at both universities was developed in conjunction with engineering deans and faculty members who teach energy science courses targeted for data collection. Course instructors allowed researchers to visit their courses to recruit students and provide a link to the survey. Students earned a 10 dollar incentive to complete the survey. To incentivize participants, relationships at both participating universities were built between research accounting offices and university card services so that students who completed the survey could be electronically incentivized via a cash transfer to their student ID's.

Students who completed the survey were asked to provide their name, ID, and course from which they were recruited. During the data collection databases of student completers were downloaded on a nightly basis and screened to guard against abuse of the incentive system. These lists were then forwarded to university card services the following morning and student incentives were deposited onto their cards. Research accounting then reimbursed card services for the cost of the incentive via a budget transfer. We also developed a procedure for cleaning and screening the data to ensure that analyses are conducted on honest student responses. We developed a protocol that combined a) variation in individual student response patterns, $b$ ) minimum word/minute reading time to meaningfully complete the survey, and c) "trigger" questions embedded in the survey, to screen data and ensure analyses are conducted on honest student responses.

The instrument was piloted in the spring of 2014 with a small group of engineering students $(n=9)$ to stress-test the website and the incentive process. The same semester, student participants were recruited and the full instrument was administered $(n=551)$ to student participants from both universities. Initial data analyses were conducted on the first round of data, validity and reliability evidence was examined, and major revisions were made to the instrument based on the results. The revised instrument was administered again in fall 2014 $(n=568)$ to engineering students from both participating universities. These data were analyzed, validity and reliability evidence was examined, and another round of minor adjustments were made the instrument. In spring 2015, the final instrument was administered $(n=410)$ to engineering students from both participating universities. Over the life of the project, data was collected from a total of 1529 engineering students from both universities. Data cleaning and coding produced a total of 1365 usable data points.

\section{Sampling and Analysis}

We utilized a stratified sampling technique with classroom and student levels. At the classroom level we purposively targeted courses with an energy focus. We were able to successfully gather data from all of our targeted courses in both universities over the life of the project, meeting our sampling goals and providing adequate variance for between classroom measures, and adequately matched samples for between university comparisons. Table 2 lists the courses targeted for data collection in the project proposal, and lists the percentage of student data were gathered in each course. Table 3 lists the gender and ethnicity data for the project data, separated by participating university.

Table 2

Courses targeted for recruiting survey participants and percent data collected 


\begin{tabular}{lrlr} 
Research University \#1 & $\%$ & Research University \#2 & $\%$ \\
\hline Engineering Mechanics I & 24.7 & Engineering Mechanics & 42.1 \\
Dynamics of Rigid Bodies & 10.7 & Solid Mechanics & 6.7 \\
Fluid Mechanics & 9.9 & Fluid Mechanics & 1.1 \\
Thermodynamics & 10.2 & Thermofluids I & 39.0 \\
Heat Transfer & 8.1 & Principles Mechanical Design & .2 \\
Energy Science Laboratory & 3.0 & Energy Systems Design & 2.6 \\
Intermediate Thermodynamics & 1.1 & Thermofluids II & .5 \\
Applied Combustion & 2.1 & Computational Fluid Dynamics & 3.2 \\
Renewable Energy & 2.1 & Renewable Energy Engineering & 2.7 \\
Other & 21.6 & Other & 1.6 \\
\hline Total Recruitment: & $\mathrm{n}=704$ & Possible Recruitment Pool: & $\mathrm{n}=661$ \\
\hline Note. Table represents all possible course data from the project with combined sections yielding student \\
total percentages in rows. R1 = GSU; R2 = ASU; Other courses for University \#1 include a) computing \\
for engineers 1.8, b) engineering graphics 15.3 c) program design for engineers 4.5. Other courses for \\
University \#2 include a) Structure mechanics .5 and b) Wind Energy 1.1.
\end{tabular}

Table 3

Ethnicity and gender percentages for project data

\begin{tabular}{lrr}
\hline & \%R1 & $\% \mathrm{R} 2$ \\
\hline American Indian/Alaska Native & 1.0 & 1.1 \\
Asian & 4.8 & 8.4 \\
Black or African American & 26.1 & 1.4 \\
Hispanic (of any race) & 6.3 & 16.5 \\
Native Hawaiian/Pacific Islndr & 0.3 & 0.2 \\
Two or More Races & 1.3 & 5.0 \\
Unknown & 2.0 & 5.9 \\
White & 58.2 & 59.1 \\
Male & 86.3 & 82.0 \\
\hline Note: Table represent all possible data from the project reported in \\
the form of percentages; R1 = GSU and R2 = ASU; differences in \\
ethnic breakdown of the sample represent regional differences in \\
culture and ethnicity described in the project proposal.
\end{tabular}

Data were analyzed after each administration of the instrument including analysis of descriptive statistics, bivariate correlations, and the underlying latent factor structure of the engagement items - typical psychometric approaches to data analysis. See [5] for a summary. Evidence for concurrent and discriminate validity was developed by analyzing the shared variance between our new engagement items and existing instruments, as well as examining the relationship between our engagement items and the instructional approaches items and example scenarios. These results were used to make adjustments to the instrument. Using data collected from the final administration of the instrument, analysis of the data continued through the summer and early fall of 2015, where the factor structure of the new instrument was re-examined, and correlational data provided construct validity evidence for the final set of items. Confirmatory factor analysis was used to confirm the factor structure of the engagement items, an invariance analysis was conducted to develop evidence for domain general nature of the construct (i.e. generalizability), and multiple regression was used to examine the mediational relationships between instruction, group level engagement, and student innovation. We summarize many of these key findings below.

\section{Theoretical Model and Significant Findings}




\section{A Theoretical Model of Interactive Engagement}

To develop a guiding theoretical model for interactive engagement, we explored complexity theory in the social and natural sciences and examined domain general properties of emergence applicable to collaboration and teamwork in engineering classrooms [11-16]. Complex systems theory suggests group-level patterns emerge from agents interacting together in a system, where the underlying structure of a system is a network. Based on our review of the literature and classroom observations, we focused on four latent constructs (i.e. variables) we hypothesized to underlie interactive engagement: self-organization, connectivity, complexity, and adaptivity. The first two dimensions, self-organization and connectivity, describe the structure and the quality of the network that surrounds the respondents. The second two dimensions, complexity and adaptivity, were developed to describe the individual's perception of group behavior and how ideas evolve within a system. See figure 1 for a summary of the model. In a nutshell, the working hypothesis was that students connect with each other to self-organize into complex working groups that adapt to solve problems. Innovative instructional strategies that promote interactive learning were hypothesized to promote complex and adaptive group behavior. In turn, complex and adaptive group behavior were hypothesized to lead to classroom innovation.

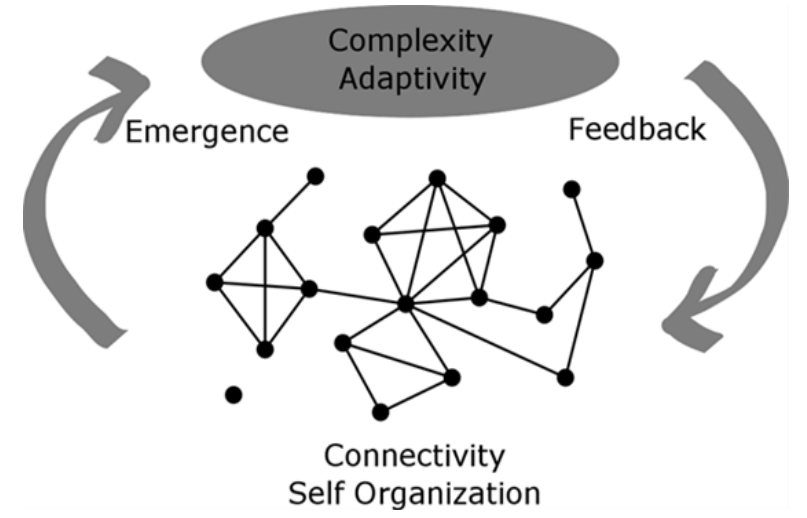

Figure 1. Project theoretical model based on complex systems theory.

Our factor analytic findings suggested that student responses to the interactive engagement items reflected two underlying dimensions associated with complex and adaptive group behaviors [5]. Analysis of classroom student networks using random graph modeling suggested that students self-organize into small groups or "communities", and that students who are more connected within those networks self-report higher levels of cognitive processing and collaboration [6]. Moreover, analysis of correlations between complex and adaptive forms of interactive engagement and established measures of cognitive, affective, and behavioral engagement [17] provided evidence that individually engaged students are more likely to self-report complex and adaptive interactive engagement. Taken together, these findings provide reliability and validity evidence that the interactive engagement assessment items produce sound evidence for our theoretical model. Below we review our findings for the relationships within our domain general innovative engagement model 1) instructional strategies $\rightarrow$ interactive engagement and 2) interactive engagement $\rightarrow$ innovation. 


\section{Instructional Strategies $\rightarrow$ Interactive Engagement}

Students were asked to respond to nine innovative instructional strategies commonly used by engineering education professors [18]. Students responded to how often they engaged in these forms of instruction in their classrooms. Factor analysis suggested a two factor solution to students' responses to the instructional strategy items, interpreted as active and interactive learning. Interactive learning was significantly and positively related to complex and adaptive engagement, suggesting that innovative instructional strategies advanced in the engineering education literature produce higher levels of student engagement [19]. Students also read four short classroom scenarios that described examples of interactive engagement. These scenarios were aligned with the following ABET student outcomes: c) an ability to design a system, component, or process to meet desired needs within realistic constraints such as economic, environmental, social, political, ethical, health and safety, manufacturability, and sustainability; d) an ability to function on multidisciplinary teams; e) an ability to identify, formulate, and solve engineering problems; k) an ability to use the techniques, skills, and modern engineering tools necessary for engineering practice. Students were then asked to rate how closely the group processes described in the scenarios (i.e. those processes described in the ABET outcomes) matched their experiences in the classroom. Their ratings of these scenarios were then compared to their responses to the complex and adaptive interactive engagement, which were also oriented toward their classroom experiences. Correlation coefficients for these comparisons ranged from .26 and .37 for the complexity items, and .34 and .46 for the adaptivity items, and .36 to .45 for the innovation items, providing further evidence for the qualitative nature of the types of classroom experiences related to innovative instructional strategies, and how the strategies are related to ABET standards for team problem solving.

\section{Interactive Engagement $\rightarrow$ Classroom Innovation}

Bivariate correlations suggested that student perceptions of their classroom groups as being complex and adaptive (i.e. latent dimensions) predicted a moderate to large amount of variance in student innovation (i.e. feeling inventive and creative) in the classroom. The statistical combination of the two variables was significant, accounting for $70 \%$ of the variation in the innovation outcome variable. Adaptively accounted for $90 \%$ of the total variance accounted for by the linear combination of the constructs. Additionally, multiple linear regressions suggested that student perceptions of group adaptivity may moderate the relationship between group complexity and student innovation. Zero order bivariate correlations indicated a strong positive relationship between group complexity and student innovation, yet the results of the multiple linear regression indicated that when controlling for group adaptivity, the relationship became negative. One way to interpret this finding is that complex groups may be more adaptive to a certain extent, crossing some threshold where they become less innovative. These results are targeted for additional analyses and research. Further analyses showed that the linear combination of adaptive group functioning and interactive teaching strategies predicted student innovation over and above affective, cognitive, or behavioral forms of engagement common in the literature See $[18,19,20]$ for a review of these findings.

\section{Discussion}


Within STEM education research, studies have produced myriad findings with regard to the impact of instruction on student engagement, and in turn how student engagement might influence learning and achievement. The purpose of the current project was to extend existing theories of student engagement by targeting a new level of analysis focused on interaction between students, as opposed to the individual actions of students. Our goal was to provide evidence for an interactive conceptualization of engagement that can be measured with a high degree of certainty using our new assessment instrument and accompanying technical manual.

Our research over the last two years suggests that targeting the ties between students as a level of analysis can provide better insights into how students learn to innovate in the classroom than measuring single individual level predictors. Our analyses suggest that the complexity of engineering student group composition, and how they adapt with their peers to solve given problems account for more variation in student innovation in our sample than individual level engagement variables, as measured by the assessment instrument we produced. Complexity and adaptivity seem to be important qualities of student classroom interaction that expose them to new ideas and ways of thinking. Additionally, our results suggest that complexity and adaptivity are significantly and positively correlated with interactive teaching strategies, providing good evidence that so-called "innovative teaching" in post-secondary education influences students to think and feel more innovative.

These results have informed post-secondary engineering education, both with regard to teaching and research, by introducing a new way of operationalizing engagement and an instrument for measuring it in a trustworthy way. Educational psychologists typically focus on individual level psychological constructs, such as motivation, self-regulation, strategy use, and cognition, as well as engagement, for measurement. Educational psychological theories that do target higher levels of analysis, such as ecological or sociocultural theories, are not generally studied from a psychometric perspective. This combination of factors, or something like it, has led some, in recent decades, to begin to question the relevance of educational psychological research - it may be unclear how teachers can use empirical evidence from the discipline to make substantive impacts on students. Efforts intended to, for example, improve motivation or help students set achievement goals, seem to only influence learning in small and perhaps negligible ways when targeted in isolation.

Similar to the way that studying the microscopic contours on the surface of a set of dice might improve a person's ability to predict the outcome of rolling them in some miniscule way, studying nuanced, individualized constructs which amount to minor signals amidst a lot of noise in a learning environment may only provide so much insight into how to make meaningful change. Moreover, examining individual level constructs, because that is where the light is good, may be a doubled edged sword because while the conclusions provide good insight into cognitive processes, there is reason to doubt if they lead to better decision making on behalf of educators. Targeting new macro levels of analysis, as we have done in this project, which can help to operationalize cross cutting variables that teachers can use to reconceptualize learning processes on a more accessible, global plane may be akin to understanding the concept of probability in the dice rolling metaphor. While the surface contours of the dice may be fascinating, knowing the probability leads to better judgment in situ.

Along these lines, this project exemplifies how focusing on the right kinds of macro variables 
that explain larger portions of variation in learning outcomes that have social significance, like learning to innovate, can move education research forward. Taking cues from other natural and social science disciplines, and operationalizing variables that target systems levels of analysis and ties between individuals or groups of individuals, can improve our ability to make smarter, more effective decisions in the post-secondary STEM classroom.

\section{References}

1. Bjorklund, S. A., \& Fortenberry, N. L. (2005). Final report: Measuring student and faculty engagement in engineering education. Center for the Advancement of Scholarship on Engineering Education, Washington, DC: National Academy of Engineering.

2. Fredricks, J. A., Blumenfeld, P. C., \& Paris, A. H. (2004). School engagement: Potential of the concept, state of the evidence. Review of educational research, 74(1), 59-109.

3. Henderson, C., Beach, A., \& Finkelstein, N. (2011). Facilitating change in undergraduate STEM instructional practices: An analytic review of the literature. Journal of Research in Science Teaching, 48(8), 952-984.

4. Hilpert, J. \& Husman, J. (in press). Instruction and engagement in post-secondary engineering classrooms: The complexity underlying small effect sizes. Empirical article accepted for publication to Educational Psychology.

5. Hilpert J., \& Husman, J. (2015). A group-level framework for emergent properties of interactive learning. Proceeding published from the invited NSF grantees session of the American Society of Engineering Educators annual conference to be held in Seattle, WA.

6. Hilpert, J., \& Holiday, R., (2015). Using Havel-Hakimi to graph classroom networks. Proceeding published in the annual proceedings of the American Society of Engineering Educators annual conference, Seattle, WA.

7. Sawyer, R. K. (2004). The mechanisms of emergence. Philosophy of the Social Sciences, 34(2), 260282.

8. Frenken, K. (2006). Technological innovation and complexity theory.Economics of Innovation and New Technology, 15(2), 137-155.

9. EAC (2011). Criteria for accrediting engineering programs: effective for Reviews During the 20122013 Accreditation Cycle. Accessed from, http://www.abet.org/, May 16 ${ }^{\text {th }}, 2012$.

10. Hilpert, J., \& Husman, J. (2016). A Systems Approach to a Self-Report Measure of Interactive Student Engagement. Abstract accepted to the Envisioning the Future of Undergraduate STEM Education: Research and Practice Symposium, Washington DC.

11. Borrego, M., Karlin, J., McNair, L. D., \& Beddoes, K. (2013). Team effectiveness theory from industrial and organizational psychology applied to engineering student project teams: A research review. Journal of Engineering Education, 102(4), 472-512.

12. Davis, B., \& Sumara, D. J. (2006). Complexity and education: Inquiries into learning, teaching, and research. Psychology Press.

13. Dillenbourg, P. (1999). Collaborative Learning: Cognitive and Computational Approaches. Advances in Learning and Instruction Series. Elsevier Science, Inc., PO Box 945, Madison Square Station, New York, NY 10160-0757

14. Mitchell, M. (2009). Complexity: A guided tour. Oxford University Press.

15. Pentland, A. (2014). Social Physics: How Good Ideas Spread-The Lessons from a New Science. Penguin.

16. Watts, D. J. (1999). Small worlds: the dynamics of networks between order and randomness. Princeton university press.

17. Wang, Z., Bergin, C., \& Bergin, D. A. (2014). Measuring engagement in fourth to twelfth grade 
classrooms: The Classroom Engagement Inventory. School Psychology Quarterly, 29(4), 517-525.

18. Borrego, M., Froyd, J. E., \& Hall, T. S. (2010). Diffusion of engineering education innovations: A survey of awareness and adoption rates in US engineering departments. Journal of Engineering Education, 99(3), 185-207

19. Hilpert, J. (2016). A Multivariate Examination of Active and Interactive Learning and Student Engagement in Post-Secondary Engineering Energy Science Classrooms: The Impact of Instructional Strategy Use. Proceeding accepted to the American Society of Engineering Educators, New Orleans, LA

20. Hilpert, J., \& Husman, J. (2016). Student Perceptions of the Emergent Properties of Interactive Learning during Classroom Group Work. Paper accepted as poster to the annual meeting of the American Education Research Association, Washington, DC. 